\title{
Physical Resistance Analysis Of Football Players In Ssb Abhiseva U-16 Limun Cage Bengkulu City
}

\section{Analisis Ketahanan Fisik Pemain Sepak Bola Pada Ssb Abhiseva U- 16 Kandang Limun Kota Bengkulu}

\author{
Anggi Oxiander ${ }^{1)}$, Mesterjon ${ }^{2)}$, Mariska \\ Febrianti ${ }^{3}$ \\ 1,2,3 Departemen Phsycal Education Study Program, Universitas \\ Dehasen Bengkulu, Bengkulu, Indonesia
}

Corresponding Author: :

mesterjon@unived.ac.id

\section{How to Cite :}

Oxiander, Anggi, Mesterjon \& Febrianti, Mariska. (2021). Physical Resistance Analysis Of Football Players In Ssb Abhiseva U-16 Limun Cage Bengkulu City. Hanoman Journal: Phsycal Education and Sport, 2 (1) 2021 page: 13-18. DOI: https://doi.org/10.37638/hanoman.2.1.13-18

\section{ARTICLE HISTORY Received [21 May 2021] Revised [23 May 2021] Accepted [21 June 2021]}

Kata Kunci :

Ketahanan Fisik, Sepak Bola.

Keywords :

Physical Endurance, Football.
This is an open access article under the $\underline{C C-B Y-S A}$ license

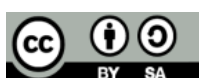

\section{ABSTRAK}

Penelitian ini bertujuan untuk mengetahui ketahanan fisik pemain sepak bola pada SSB Abhiseva Kandang Limun Kota Bengkulu.Penelitian ini merupakan penelitian deskritif kuantitatif. Metode yang digunakan adalah metode analisis. Subjek penelitian ini adalah pemain SSB Abhiseva Kandang Limun Kota Bengkulu yang berjumlah 24 orang. Instrument yang digunakan adalah bleep test. Teknik analisis yang dilakukan adalah menuangkan frekuensi kedalam bentuk diagram batang. Hasil penelitian ini menunjukan bahwa tingkat daya tahan tubuh pada pemain SSB Abhiseva Kandang Limun Kota Bengkulu adalah sangat kurang dengan pertimbangan frekuensi terbanyak pada kategori kurang sekali dengan 18 orang atau 75\%. Analisis Ketahanan Fisik Pemain Sepak Bola Pada SSB Abhiseva Kandang Limun Kota Bengkulu yang berkategorikan baik sekali 0 orang atau 0\%, baik 0 orang atau 0\%, sedang 0 orang atau 0\%, kurang 6 orang atau $25 \%$, kurang sekali 18 orang atau $75 \%$.

\section{ABSTRACT}

This research is a quantitative descriptive research. The method used is the method of analysis. The subjects of this study were 24 SSB Abhiseva U-16 players in Bengkulu City. The instrument used was the Bleep Test. The analysis technique used is to pour the frequency into the form of a bar chart. The results of this study indicate that the level of endurance of SSB Abhiseva Kandang Limun players in Bengkulu City is very low considering the highest frequency with very low category with 18 people or $75 \%$. Analysis of the Physical Endurance of football players at SSB Abhiseva Kandang Limun in Bengkulu City which is categorized as very good 0 people or $0 \%$, either 0 people or $0 \%$, moderate 0 people or $0 \%$, less 6 people or $25 \%$, less 18 people or $75 \%$. 


\section{PENDAHULUAN}

Olahraga adalah bagian yang tidak dapat dipisahkan dari kehidupan manusia. Hal ini dikarenakan olahraga merupakan unsur penting dalam pemeliharaan kesehatan manusia. Salah satu cabang yang mendapat perhatian besar dari berbagai kalangan adalah olahraga sepak bola. Hal ini dikarenakan cabang olahraga sepak bola merupakan cabang olahraga paling populer dibandingkan cabang olahraga yang lain. Olahraga ini dapat membantu menjaga kebugaran tubuh, seperti: daya tahan paru-jantung, fleksibilitas, kekuatan otot, dan daya tahan otot. Selain itu dapat melatih komponen kebugaran jasmani dalam tubuh yang berhubungan dengan keterampilan, seperti: kecepatan, daya ledak, keseimbangan, kelincahan, serta koordinasi, sehingga secara tidak langsung pada saat kita bermain sepak bola komponen-komponen dalam tubuh baik yang berhubungan dengan kesehatan maupun yang berhubungan dengan keterampilan akan terlatih, sehingga dapat menjaga tubuh tetap sehat dan bugar.

Permainan sepakbola adalah permainan beregu yang mempunyai tujuan untuk memasukkan bola sebanyak-banyaknya ke gawang lawan dan mempertahankan gawang sendiri supaya tidak kemasukkan bola, dan kelompok yang paling banyak memasukkan bola keluar sebagai pemenang (Clive Gifford, 2002: 11). Daya tahan merupakan salah satu unsur penting dalam sepakbola. Menurut Komarudin (2011: 59) Daya tahan menunjuk pada kemampuan cardiorespiratory (jantung dan paru) atau pada daya tahan otot (muscular endurance). Berdasarkan hasil observasi, siswa sekolah sepakbola (SSB) Abhiseva U-16 Kandang Limun latihan dilaksanakan dua kali per minggu yaitu hari senin sore dan minggu sore, dengan waktu tatap muka 90 menit dengan di dampingi oleh pelatih Bapak Roni Syaputra, tempat latihan di lapangan Universitas Bengkulu, Kota Bengkulu, memiliki daya tahan tubuh yang kurang bagus, sehingga berpengaruh terhadap rendahnya stamina hal ini ditandai dengan turunya kordinasi, konsentrasi dan mudah terengah-engah. Hal tersebut dikarenakan pelatih jarang memberikan latihan untuk peningkatan daya tahan sebagai suatu rangkaian awal sebelum mengajarkan atau melatih teknik dasar sepakbola. Daya tahan tubuh yang baik hanya dapat diperoleh melalui proses latihan. Daya tahan merupakan salah satu komponen biomotor utama/dasar dalam setiap cabang olahraga. Komponen biomotor daya tahan pada umumnya digunakan sebagai tolok ukur untuk mengetahui tingkat kebugaran jasmani (physical fitnes) olahragawan. Daya tahan ditinjau dari kerja otot adalah kemampuan kerja otot atau sekelompok dalam jangka waktu tertentu, sedangkan pengertian daya tahan dari sistem energi adalah kemampuan kerja organ-organ tubuh dalam jangka waktu tertentu. Berdasarkan dua pengertian tersebut maka daya tahan didefinisikan sebagai kemampuan peralatan organ tubuh untuk melawan kelelahan selama berlangsungnya aktivitas atau kerja.

Klub merupakan ujung tombak pembinaan karena merupakan organisasi yang kedudukannya berada pada posisi paling depan, merupakan wadah 
pembinaan yang secara langsung berhadapan dengan atlet (Guntur, 2007: 251-252). Sekolah sepakbola (SSB) merupakan sebuah organisasi olahraga khususnya sepakbola yang memiliki fungsi mengembangkan potensi yang dimiliki atlet. Tujuan sekolah sepakbola untuk menghasilkan atlet yang memiliki kemampuan yang baik, mampu bersaing dengan sekolah sepakbola lainnya, dapat memuaskan masyarakat dan mempertahankan kelangsungan hidup suatu organisasi (Soedjono, 1999: 2).

Penerapan fisik merupakan salah satu faktor yang sangat penting dalam latihan untuk mencapai suatu prestasi yang tinggi. Kondisi fisik merupakan program pokok untuk pembinaan atlet untuk berprestasi dalam suatu cabang olahraga. Menurut Sajoto (1989: 57) "kondisi fisik salah satu prasarat yang sangat diperlukan dalam setiap usaha peningkatanprestasi seorang atlit, bahkan dikatakan dasar landasan titik tolak suatu awalan olaraga prestasi".bedasarkan pendapat para ahli dapat dikemukakan bahwa kondisi fisik merupakan semua kemampuan jasmani yang menentukan prestasi yang realisasinya dilakukan melalui kemampuan pribadi. Kemapuan awal kondisi fisik merupakan ukuran/pedoman untuk membuat perencanaan latihan. Suatu analisa keadaan awal secara umum terhadap hasil-hasil pertandingan yang lalu diperlukan untuk mengembangkan prestasi dalam masamasa kompetisi.

\section{METODE PENELITIAN}

Metode penelitian ini adalah penelitian deskriptif kuantitatif, tujuanya adalah untuk melihat atau menganalisis tingkat daya tahan tubuh siswa di SSB Abhiseva Kandang Limun Kota Bengkulu. Populasi penelitian ini adalah siswa di SSB Abhiseva U-16 yang berjumlah 24 Orang. Apabila subjeknya kurang dari 100 lebih baik diambil semua. Sebaliknya jika subjeknya lebih besar dari 100 dapat diambil antara 10-15\% atau $20-25 \%$. Teknik pengambilan sampel dalam penelitian ini adalah dengan cara mengikutsertakan semua individu atau anggota populasi menjadi sampel yang berjumlah 24 orang . Jadi penelitian ini disebut sebagai penelitian populasi dengan teknik pengambilan data total sampling.

\section{HASIL}

Data penelitian untuk skor volume oksigen maksimal(Vo2max), didapatkan data bahwa skor tertinggi level 6 shuffle 7 dengan VO2MAX 35,4 dan skor terendah level 4 shuffle 8 dengan VO2MAX 29,1. Dari analisis data diperoleh rata-rata (Mean) sebesar 29,5. Distribusi frekuensi data volume oksigen maksimal (VO2MAX) pemain sepak bola pad SSB Abhiseva Kandang Limun Kota Bengkulu. 6 orang (25,0\%) berada pada skor (29,1-30,5). 3 orang (12,5\%) berada pada skor $(30,6-32,3)$. 5 orang $(20,8 \%)$ 
berada pada skor $(32,4-32,8) .4$ orang $(16,7 \%)$ berada pada skor $(32,9-34,2)$. 6 orang $(25,0 \%)$ berada pada skor $(34,3-35,4)$.

Tabel 1. Norma Tes Dari Hasil Penelitian Melihat Volume Oksigen Maksimal

\begin{tabular}{ccccc} 
No & Norma Tes & $\begin{array}{c}\text { Kelas } \\
\text { Interval }\end{array}$ & $\begin{array}{c}\text { Frekuensi } \\
\text { Absolut }\end{array}$ & $\begin{array}{c}\text { Frekuensi } \\
\text { Relatif }(\%)\end{array}$ \\
\hline 1 & Baik Sekali & $>48$ & 0 & 0 \\
2 & Baik & $42-47$ & 0 & 0 \\
3 & Sedang & $38-41$ & 0 & 0 \\
4 & Kurang & $33-37$ & 6 & $25,0 \%$ \\
5 & Kurang Sekali & $<32$ & 18 & $75,0 \%$ \\
\hline
\end{tabular}

Sumber: Data Diolah, 2020

\section{PEMBAHASAN}

Sepakbola adalah sesuatu permainan yang dilakukan dengan jalan menyepak, yang mempunyai tujuan untuk memasukkan bola ke gawang lawan dengan mempertahankan gawang agar tidak kemasukkan bola. Sejalan dengan pendapat tersebut menunjukan bahwa tugas seorang pemain sepakbola yaitu harus mampu melakukan teknik dengan bola dan teknik tanpa bola dengan baik yang bertujuan untuk mencentak gol sebanyak mungkin di gawang lawan dan menjaga gawang dari kebobolan. Tujuan utama dalam permainan sepakbola ini yang menjadikan pemain sepakbola ini menjadikan pemain sepakbola secara kolektif harus mampu memiliki skill, mental dan kondisi fisik secara prima agar dapat bermain dalam tim dengan baik. Pola pergerakan sepakbola yang berat dan lebih sering mendapatkan gangguan dari lawan ini yang akan mempengaruhi kualitas pemain tersebut.

Bermain sepakbola tidak cukup hanya dengan memiliki skill yang baik saja tetapi membutuhkan dukungan secara menyeluruh agar dapat bermain dengan baik. Menurut Mochamad Sajoto (1999:13), kondisi fisik adalah salah satu prasyarat yang sangat diperlukan dalam usaha peningkatan prestasi seorang atlet, bahkan sebagai landasan titik tolak suatu awalan olahraga prestasi. Raihan prestasi yang tinggi seorang atlet dan tim sepakbola akan tergantung terhadap kemampuan dan kondisi fisik akan menjadi faktor yang berpengaruh besar terhadap prestasi atlet. Program latihan yang teratur dan terkontrol dengan baik akan mampu meningkatkan kemampuan dan kondisi fisik pemain untuk dapat menampilkan kemampuan bermainnya dengan maksimal. Penelitian ini merupakan deskriptif kuantitatif dimana pengambilan data menggunakan tes volume oksigen maksimal menggunakan bleep tes. Tujuan penelitian ini untuk mengetahui tingkat daya tahan

16 | Oxiander, Anggi, Mesterjon \& Febrianti, Mariska. (2020). Physical Resistance Analysis Of Football... 
tubuh pemain sepak bola pada pemain SSB Abhiseva Kandang Limun. Berdasarkan data hasil analisi menunjukan bahwa tingkat volume oksigen maksimal masuk dalam kategori "Kurang sekali" dengan rata-rata "skor 32,08". Hal ini kemungkinan disebabkan oleh beberapa factor yang mempengaruhi, yaitu:

1. Faktor Internal yaitu faktor dari pemain itu sendiri. Motivasi dan minat pemain dalam mengikuti kegiatan latihan dapat mempengaruhi ketahanan fisik pemain tersebut.

2. Faktor Eksternal yaitu: Pelatih, tugas pelatih adalah memberikan motivasi kepada pemain agar pemain lebih serius lagi dalam mengikuti kegiatan latihan seperti menjaga kondisi fisik pemain di masa pandemi ini. Lingkungan, lingkungan juga mempengaruhi kondisi fisik pemain, contohnya saja jika pemain berada dilingkungan yang kurang baik, maka kondisi fisik pemain juga kurang baik, dan apa bila pemain berada dilingkungan yang baik, maka kondisi fisik pemain bisa dibilang baik juga Saran dan prasarana, keterbatasan sarana saat pandemi juga berpengaruh terhadap kondisi fisik pemain, karna disaat pandemi pemain juga kurang berolahraga karna sarana dan prasananya kurang.

\section{KESIMPULAN DAN SARAN}

Berdasarkan penelitian yang telah dilakukan dengan analisis data maka, diperoleh data tingkat kemampuan daya tahan tubuh pemain SSB Abhiseva U-16 Kandang limun kota Bengkulu dengan hasil berkategorikan baik sekali 0 orang atau $0 \%$, baik 0 orang atau $0 \%$, sedang 0 Orang atau $0 \%$, kurang 6 orang atau 25\%, sangat kurang 18 orang atau 75\%. Dari pembahasan dapat disimpulkan bahwa tingkat daya tahan tubuh pemain SSB Abhiseva Kandang Limun dengan 24 orang sampel dan rata-rata 32,08 pada kategori Kurang Sekali. Bagi atlet, agar atlet lebih bersemangat dalam menjaga kondisi fisik walaupun sedang pandemi. Bagi pelatih, semakin ditingkatkan kembali bentuk-bentuk latihannya. Bagi peneliti, selanjutnya dapat mengembangkan penelitian ini dengan menambah unsur-unsur yang lebih luas.

\section{DAFTAR PUSTAKA}

1. Guntur. 2007. Peranan Manager dalam Klub Bolavoli. Majalah IImiah Olahraga.Vol. 13 No. 2. HIm 251-252.

2. Gifford, Clive. 2003. Football, The Ultimate Guide to the Beautiful Game. (Rudijanto, Terjemahan). Jakarta. Erlangga. Buku asli diterbitkan tahun 2002.

3. Komarudin. 2011. Dasar Gerak Sepakbola. Yogyakarta: Universitas Negeri Yogyakarta 
4. Soedjono. 1999. Konsep Pembinaan Sepakbola Usia Dini. Makalah.Yogyakarta: FPOK IKIP. Sukadiyanto. 2009. Metode Melatih Fisik Petenis. Yogyakarta: FIK UNY.

5. Sajoto. 1988. Peningkatan dan Pembinaan Kekuatan Kondisi Fisik dan Olahraga. Semarang: Dahara Prize. 